\title{
Organização espacial em comunidades camponesas de Santo Antônio de Leverger-MT
} Spatial Organization in peasant communities of Santo Antônio do Leverger-MT Organización espacial en comunidades campesinas de Santo Antônio de Leverger-MT Organisations spatiales dans des communautés rurales de Santo Antônio de Leverger-MT

\author{
Hérica Clair Garcêz Nabuco* \\ Rodrigo Aleixo Brito de Azevedo** \\ Maria Cristina de Figueiredo e Albuquerque ${ }^{* * *}$ \\ José Carlos Leite**** \\ Carla Cella ${ }^{* * * *}$
}

Recebido em 23/3/2009; revisado e aprovado em 30/5/2009; aceito em 31/7/2009

\begin{abstract}
Resumo: Este artigo investiga a percepção e a forma de organização espacial em duas comunidades camponesas localizadas no estado de Mato Grosso. A partir da memória oral, da história de ocupação e domínio territorial dessas comunidades, verificou-se que, de modo geral, a organização espacial dessas comunidades resulta da influência de três elementos: da relação de parentesco; da influência das instituições sociais na comunidade e da presença ou ausência dos aspectos naturais.

Palavras-chave : Comunidade Sangradouro. Comunidade São Sebastião. Campesinato.

Abstract: Abstract: This article investigates the perception and shape of spatial organization in two peasant communities located in the state of Mato Grosso. From the oral memory, the history of occupation and territorial dominion of these communities, it was verified that, in a general way, the spatial organization of these communities is a result of three elements: kinship relationship, the influence of social institutions in the community and the presence or absence of the natural aspects.

Key-words: Sangradouro Community. São Sebastiao Community. Campesinato.

Résumé: Cet article enquête la perception et la forme d'organisation spatiale dans deux communautés rurales situées dans l'État du Mato Grosso. À partir de la mémoire orale, de l'histoire de l'occupation et de la domination territoriale de ces communautés, on a constaté que, en général, l'organisation spatiale de ces communautés résulte de l'influence de trois éléments : du rapport familial ; de l'influence des institutions sociales dans la communauté et de la présence ou absence des aspects naturels.

Mots-clés: Communauté Sangradouro. Communauté São Sebastião. Paysannerie.

Resumen: Este artículo investiga la percepción de la forma de organización espacial en dos comunidades campesinas localizadas en el estado de Mato Grosso, Brasil. A partir de la memoria oral y de la historia de ocupación y dominio territorial de esas comunidades, se ha verificado que, en general, la organización espacial de las mismas es resultado de la influencia de tres elementos: la relación de parentesco, la influencia de las instituciones sociales en la comunidad y la presencia o ausencia de los aspectos naturales.

Palabras clave: Comunidad Sangradouro. Comunidad São Sebastião. Campesinado.
\end{abstract}

\section{Introdução}

O arranjo espacial de uma comunidade rural camponesa é compreendido pelo pesquisador quando esse tem clareza do modelo de vida idealizado por esse grupo social. Para isso, há a necessidade de conhecer a cultura e pormenores do grupo social, porque nem sempre o pesquisador e o grupo pesquisado percebem e nomeiam os espaços da mesma forma e essa diferença de compreensão pode levar a um

\footnotetext{
* Bióloga, mestranda do curso de Pós-graduação em Agricultura Tropical, Universidade Federal de Mato Grosso, CAPES, herica.clair@gmail.com.

** Doutor em Fitotecnia, Universidade Federal Rural do Semi-Arido, Departamento de Ciências Vegetais, rabaz@ufersa.edu.br.

*** Doutora em Produção e Tecnologia de Sementes, Universidade Federal de Mato Grosso, Departamento de Fitotecnia e Fitossanidade, mcfa@cpd.ufmt.br.

**** Doutor em Comunicação e Semiótica, Universidade Federal de Mato Grosso, Departamento de Filosofia, j.leite@uol.com.br.

***** Engenheira Agrônoma, mestranda do curso de Pós-graduação em Agricultura Tropical, Universidade Federal de Mato Grosso, CAPES, cella.carla@gmail.com.
} 
distanciamento entre o investigador e o alvo pesquisado.

Os espaços sociais e agrícolas ocupados por uma comunidade precisam ser manejados e organizados segundo uma determinada lógica, a lógica do camponês que, para isso, se utiliza do corpo de conhecimento que possui. É o corpus ou sistema de conhecimento que esclarece as formas como cada camponês percebe, concebe e materializa os ecossistemas dos quais depende para viver (TOLEDO, 1991) dentro de diferentes dimensões (ALTIERI, 1991):

tem sua origem local e naturalmente. E esse conhecimento possui muitas dimensões, incluindo aspectos lingüísticos, botânicos, zoológicos, artesanais e agrícolas e se deriva da interação entre os seres humanos e o meio ambiente. A informação é extraída do meio ambiente através do sistema de cognição e percepção que selecionam a informação útil e adaptável e depois as adaptações são preservadas e transmitidas de geração em geração por meio oral ou experimental... (ALTIERI, 1991, 2p.)

Mas, é a cultura a responsável pela visão de mundo do grupo social e que determina o sistema de conhecimento desses camponeses.

$\mathrm{Na}$ ciência, três diferentes correntes operam de maneira distinta para a investigação do corpus dos camponeses. A primeira é a análise das crenças dos agricultores que é realizada por meio de processos etnográficos, com foco no estudo dos mitos; a segunda corrente é o estudo das percepções que é realizada pelos psicólogos ambientais, geógrafos e ecólogos da paisagem; e a terceira é a do estudo dos sistemas de conhecimento que é realizado pelos etnobiólogos, linguistas e geógrafos (TOLEDO, 1991). Essas três abordagens formam o tripé para o estudo e compreensão do corpus. Assim, crer, perceber e conhecer constituem as três operações intelectuais utilizadas pelo camponês para operar seu território e criar suas territorialidades na natureza (TOLEDO, 1991).

Assim, a partir do corpo de conhecimento, as pessoas têm a compreensão da maneira de fazer e realizar a sua agricultura e sua organização social. Como também, por meio do conhecimento, surgem as idéias e significados que possibilitarão a tomada de decisões e a experimentação das práticas agrícolas (praxis camponesa). Enfim, a praxis é um conjunto de práticas agrícolas e estratégias de manejo dos recursos naturais que possibilita ao camponês modificar a estrutura e o funcionamento dos ecossistemas e espaços e estabelecer seu modo de produção.

A percepção é a segunda dimensão para a compreensão do corpus dos camponeses. Ela é uma palavra erroneamente utilizada como sinônimo de conhecimento, pois, conhecimento é um processo epistemológico, enquanto a percepção é um processo psicológico. A compreensão da experiência perceptiva é diferente de pessoa para pessoa no tempo e no espaço e depende do contexto em que a pessoa que percebe está inserida (ADDISON, 2003).

Ainda conforme este autor (op cit),

a percepção do mundo é feita através de todos os sentidos, os quais variam conforme os contextos nos quais as pessoas estão inseridas. O mundo percebido pelos olhos é puramente uma relação com o objeto. A percepção e a imagem são dinâmicas no tempo e no espaço, a compreensão [...] muda concomitantemente com a idade, sexo, educação, cultura, erudição, classe social, economia, política, religião, individualidade, preferências, atitudes, valores e atribuições do meio ambiente. (ADDISON, 2003, 39p.)

Desta forma, estudar a percepção que os camponeses possuem de seus ambientes, recursos e espaços é fundamental para entender as inter-relações entre o homem e o ambiente, compreendendo suas expectativas, anseios, satisfações e insatisfações, julgamentos e condutas.

A idéia de espaço aqui exposta considera que o território não é apenas a noção de espaço concreto, físico, mas também o espaço não mensurável, espaço funcional, construído a partir das teias de relações sociais (AZEVEDO 2001; AGUIAR, 2006). Ao reconhecer tais fatos, é mais perceptível a necessidade de se estudar como os camponeses organizam os espaços, para assim facilitar a compreensão da postura que eles possuem diante dos problemas que são enfrentados para a realização de sua produção agrícola.

Portanto, o objetivo neste trabalho foi compreender a história de ocupação e domínio territorial agrícola e não agrícola das comunidades Sangradouro e São Sebastião, 
a partir da organização espacial desses camponeses.

\section{Aspectos metodológicos}

A área de estudo compreende a Comunidade Sangradouro e Comunidade São Sebastião $\left(15^{\circ} 48^{\prime} 11.6^{\prime \prime}\right.$ de latitude sul e $55^{\circ}$ $48^{\prime} 07,0^{\prime \prime}$ de longitude oeste de Greenwich), localizada a $65 \mathrm{~km}$ da cidade de Santo Antônio de Leverger-MT (Figura 1). A área total da comunidade de Sangradouro e São Sebastião está em torno de 868,98 ha (EMPAER, 2004).

A população de Sangradouro e Vila São Sebastião é constituída por moradores "nascidos e criados" na região, alguns originados de outras comunidades da Baixada Cuiabana e de outros estados do país, como Minas Gerais e São Paulo. O número de famílias na comunidade, de acordo com o diagnóstico da EMPAER (2004), é de 75 famílias.

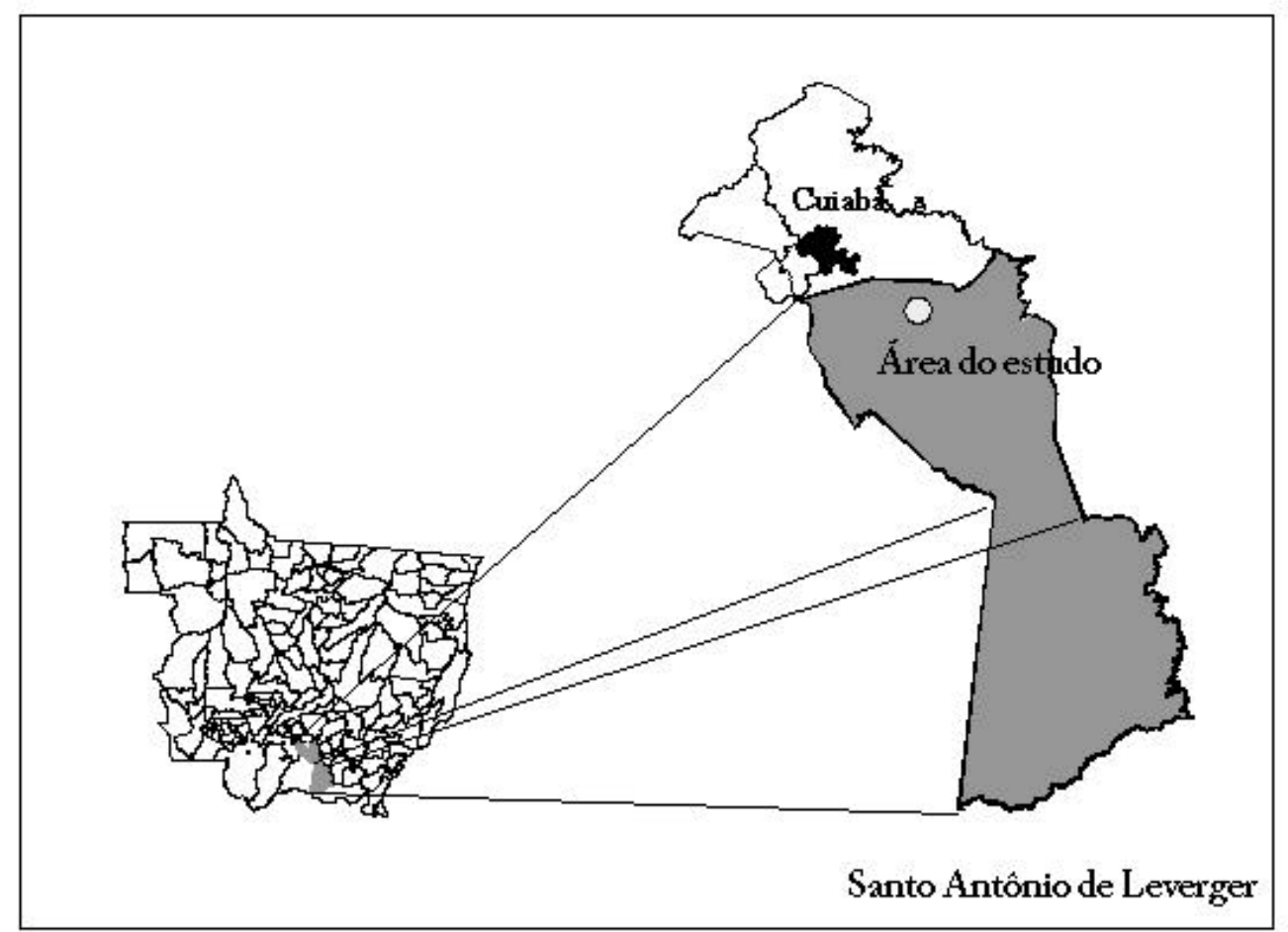

Figura 1 - Localização do município onde se deu o estudo, Santo Antônio de Leverger, no Estado de Mato Grosso.

Antes de iniciar a coleta de dados foi realizada uma visita às Comunidades Sangradouro e São Sebastião para o primeiro contato com seus moradores. A primeira conversa aconteceu com uma moradora e sua família, explicando a todos o projeto, seus objetivos e propósitos. Ao longo da conversa, a moradora explicou que a comunidade era antiga e a maioria "era nascida e criada" na região e que alguns ainda exerciam atividade de agricultura e pecuária em seus sítios.

Na segunda visita à comunidade, passou-se uma tarde na região, com a intenção de identificar elementos campesinos para posteriormente desenvolver os critérios de seleção dos informantes. Nesse dia, houve a observação da forma de distribuição das casas e uma conversa com a moradora proprietária de um estabelecimento comercial que forneceu informações sobre a vida na região, quantidade de escolas e também de moradores.

Informações bibliográficas e documentais (relatórios, questionários aplicados aos moradores e croquis) da comunidade foram cedidas pela equipe de trabalho da EMPAER de Santo Antônio de Leverger-MT que, no ano de 2004, desenvolveu um diagnóstico na região.

Na terceira à comunidade, com os critérios já estabelecidos e o guia de entrevista pronto, foram realizadas conversas com os moradores da comunidade, indo às casas e 
explicando a cada família o projeto e pedindo o aceite verbal para a realização das entrevistas. Nessa atividade já foi possível detectar características da comunidade, como a irmandade e as localidades ali existentes, a relação das pessoas com a terra e com o trabalho agrícola. Nesse dia foi usado o mínimo das cadernetas para não intimidar as pessoas; somente foi utilizado o croqui fornecido pela EMPAER pelo qual já foi possível conhecer a divisão territorial da região.

Os seguintes critérios foram estabelecidos para a escolha dos moradores a serem entrevistados:

1) Que os proprietários morassem na comunidade.

2) Que o morador tivesse conhecimento sobre a história de ocupação das comunidades.

3) Que as famílias aceitassem participar da pesquisa e tivessem disponibilidade de tempo.

4) Que o nome da família tivesse sido citado no relatório técnico da EMPAER (2004), que abrangia o universo de 75 famílias. Isso possibilitou um conhecimento prévio dos moradores que viviam na região há mais tempo.

Assim, foram entrevistadas 22 pessoas: homens e mulheres. As entrevistas ocorreram em várias etapas, de acordo com os resultados conseguidos nesse estudo. Nas primeiras etapas, já foi possível identificar a organização espacial das duas comunidades.

As entrevistas foram semiestruturadas com perguntas abertas para que os entrevistados pudessem se sentir à vontade e pudessem lembrar-se da história e das nominações usadas no seu cotidiano. A descrição final foi organizada na forma de texto no qual puderam ser identificadas, via análise textual, os principais marcos e acontecimentos que possibilitaram a organização espacial atual. Tal metodologia foi utilizada em outros trabalhos com camponeses como: Alves (2004), Bastos (2004), Costa (2004), Godoy (2004), Mendes (2005), Oliveira (2006), Ramos (2006), Vieira (2006) e Silva (2007).

\section{Resultados}

A organização espacial das duas comunidades camponesas

As comunidades Sangradouro e São Sebastião fazem parte do sistema de produção camponês identificado a partir de algumas características, conforme vasta literatura (WOLF, 1970; QUEIROZ, 1973; SHANIN, 1990; TOLEDO, 1991; WOORTMANN \& WOORTMANN, 1997; LAMARCHE, 1997; CANDIDO, 2001; SCHNEIDER, 2003; BOMBARDI, 2004; AGUIAR, 2006), a saber:

1) A terra, a família e a comunidade são as unidades básicas de interação social dentro do campesinato. Assim, a população vive no campo, não isoladamente, mas mantendo relações com parentes e vizinhos, indo até a cidade, conhecendo outros ambientes e configurações sociais diferentes.

2) A propriedade não necessita ser pequena para que o agricultor seja considerado um camponês, o importante é o tipo de exploração do solo que se faz.

3) No uso do solo, o camponês é o responsável pela lavoura, trabalha pessoalmente com a terra e com a ajuda da família e, ocasionalmente, de alguns empregados remunerados, podendo esta terra ser propriedade dele ou não.

4) O camponês entende sua unidade de produção não como um empreendimento agrícola, mas como um local de sustento da sua família.

5) A produção camponesa é geralmente feita em pequena escala, devido à escassez de tecnologia e recursos, principalmente escassez da terra.

6) O camponês não tem a obrigatoriedade em se dedicar exclusivamente às atividades ligadas à agricultura ou ao cultivo da terra, ele pode dedicar-se ao exercício de um conjunto variado de atividades econômicas e produtivas (pluriatividade).

Não houve acesso a estudos que relatassem a história dessas duas comunidades, nem ao modo como as relações sociais foram sendo estabelecidas ao longo do tempo e, muito menos, a maneira como a territorialidade foi operacionalizada por esses 
moradores. Assim, a maior parte das informações foram obtidas por meio de relatos dos moradores das duas comunidades, idosos com 70 a 85 anos. Foi possível identificar, em um primeiro momento, uma estrutura regional de organização espacial própria que, provavelmente, exista há mais de oitenta anos.

A relação de parentesco e casamentos consanguíneos é de suma importância na compreensão da organização e ocupação territorial pelos camponeses. Quanto a essa organização, Queiroz (1973) esclareceu que esse processo se inicia quando os filhos dos camponeses se casam, deixam a casa paterna e constroem sua própria habitação um pouco mais distante, em terras familiares, derrubando a vegetação existente e fazendo roça de subsistência e, por fim, formam sua própria unidade de produção. Quando a região está demasiadamente densa, os moradores tomam a decisão de construir uma igre- ja, uma vendinha, uma escola, um centro comunitário, institui novas relações sociais e o resultado disso é o estabelecimento de uma nova comunidade (QUEIROZ, 1973; BOMBARDI, 2004; AGUIAR, 2006).

De maneira semelhante, as primeiras famílias da região estabeleceram-se em Sangradouro. O nome Sangradouro relaciona-se à sangra dos rios (encontro dos rios). Os núcleos familiares espalharam-se pelo território e com a entrada de novos moradores vindos de outras comunidades da Baixada Cuiabana formaram uma nova comunidade, não tão distante dali, conhecida como Perdição.

Na primeira representação do território (Figura 2), a comunidade de Sangradouro chegava até o local onde hoje se localiza o bar do Edson, na Vila São Sebastião, abrangendo o centro comunitário e a antiga igreja São Sebastião, espaços que, hoje, fazem parte da comunidade São Sebastião.

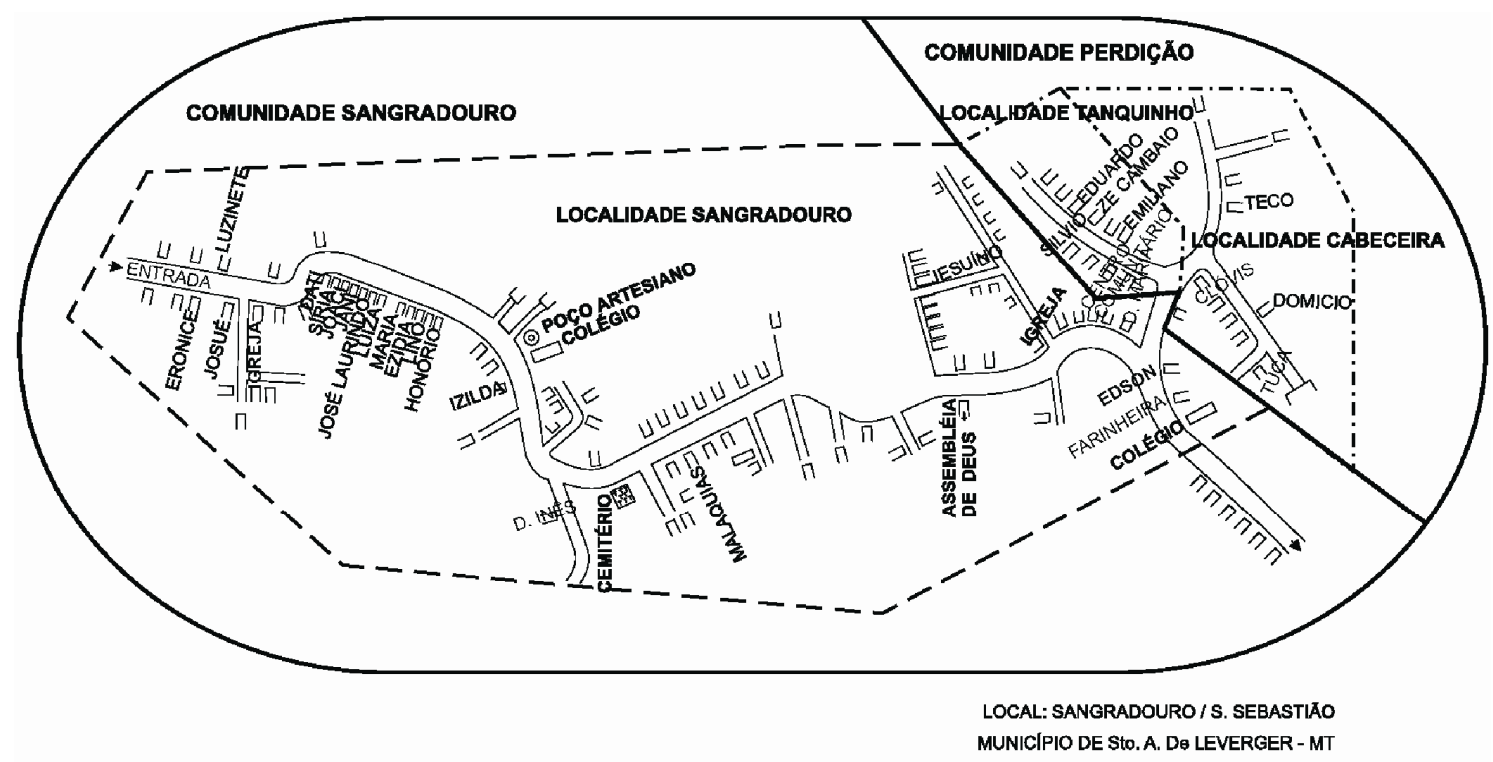

Figura 2 - Primeira divisão territorial das duas comunidades onde se deu o estudo. Fonte: elaboração própria

A comunidade Perdição recebeu esse nome por causa de um acontecimento contado em duas versões. A primeira delas conta que uma pequena menina se perdeu no meio da mata, quando resolveu seguir sua mãe que fora lavar as roupas na beira do rio. Todos da comunidade mobilizaram-se a sua procura, no entanto, só encontraram suas pegadas até certo ponto do trajeto da estrada, onde sua mãe antes havia caminhado.
A menina nunca foi encontrada e por isso, a comunidade recebeu o nome de Perdição.

A segunda versão da história conta que, antigamente, a estrada principal não era a mesma de hoje, era mais próxima da mata. Nesse tempo havia uma circulação grande de pessoas e justamente naquela região os viajantes faziam parada para descanso, o conhecido "pouso" pela estrada. Conta a história que a menina saiu de perto 
dos pais enquanto eles descansavam e se perdeu.

As duas versões contadas, além de explicar o porquê do nome da comunidade, fazem perceber características do ambiente natural e do cotidiano dos primeiros moradores que ali viviam. Assim, segundo Aguiar (2006), os nomes dos lugares traduzem as relações sensitivas das pessoas com a terra e revelam informações sobre ecologia, cosmologia e história desses lugares.

Por volta do ano de 1999, o padre da Igreja São Sebastião, juntamente com alguns moradores, convenceu a comunidade a trocar o nome da comunidade para Vila São Sebastião, em homenagem ao santo padroeiro da comunidade. Mas, não foi somente o nome da comunidade que mudou; a primeira Igreja São Sebastião foi abandonada e uma nova igreja foi construída na beira da estrada, o que causou também uma nova reestruturação territorial da região.

Na representação territorial antiga, a comunidade Perdição abrangia apenas as localidades Cabeceira, "Corgo D'ema" e Tanquinho e a localidade onde hoje é a Vila São Sebastião outrora pertencia à comunidade Sangradouro. Depois da mudança de posicionamento da igreja, a localidade Vila São Sebastião passou a pertencer à comunidade São Sebastião (Figura 3).
Alguns moradores contam que era um incômodo para a comunidade possuir o nome de Perdição, devido à ridicularização que sofriam da parte dos moradores da comunidade de Sangradouro que os apelidava de perdidos. No entanto, apesar da troca do nome para Comunidade São Sebastião, os moradores antigos da comunidade, as comunidades circunvizinhas e os moradores do centro Santo Antonio de Leverger, até hoje a chamam, ainda, de Perdição.

Atualmente, na comunidade Sangradouro, são identificadas duas localidades: a localidade Sangradouro e a localidade Cantão. Na localidade Sangradouro, a grande maioria dos seus moradores pertence à irmandade de sobrenome Pereira e de sobrenome Nascimento, existindo relações de parentesco entre essas duas irmandades, inclusive casamentos consanguíneos. Já na localidade Cantão, a irmandade é a família de sobrenome Duarte. A nomeação Cantão é dada pelos moradores de Sangradouro às famílias que moram na periferia dessa localidade, como a família Duarte que vive na divisa entre a Comunidade Sangradouro e a Comunidade São Sebastião. Irmandade é o termo utilizado pelos moradores para identificar as primeiras famílias que chegaram às comunidades.

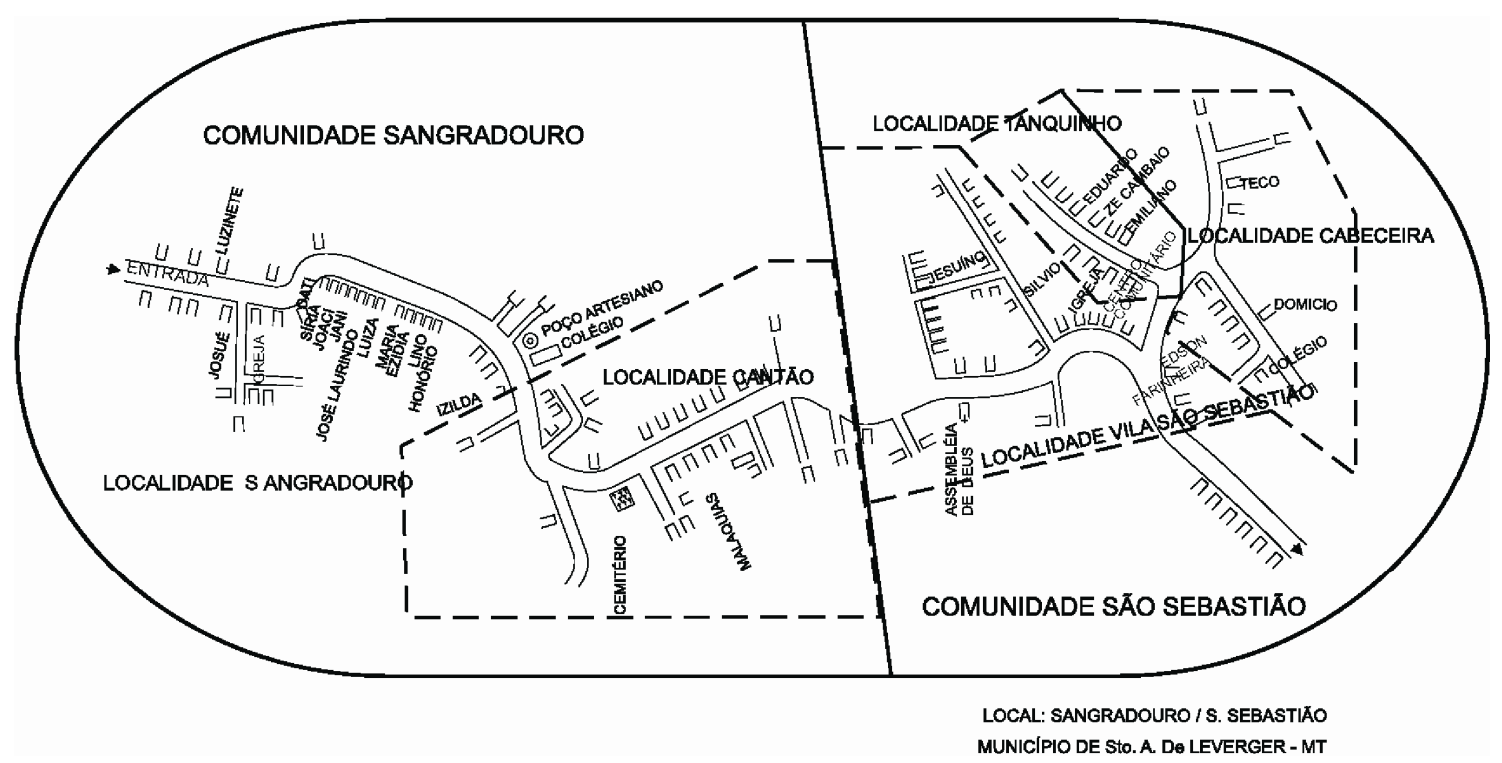

Figura 3 - Segunda divisão territorial das duas comunidades onde se deu o estudo. Fonte: elaboração própria 
Na comunidade São Sebastião foram identificadas mais quatro localidades: Vila São Sebastião, Tanquinho, Córrego das Emas e Cabeceira. As relações religiosas e comerciais dessa comunidade ocorrem na localidade Vila São Sebastião. Nessa localidade existe um bar, duas igrejas, a Igreja Católica São Sebastião e a Igreja Evangélica da Assembléia de Deus, e uma escola que ainda não possui nome, mas que os moradores denominam de Escola Municipal Perdição.

A localidade Tanquinho recebeu esse nome devido à presença de um tanque para o gado beber água feita no tempo em que a terra não havia sido desmembrada para os herdeiros da família Magalhães de Almeida. Já a localidade Córrego das Emas recebeu esse nome devido à existência de um córrego e a presença de emas (Rhea americana) na região. Os moradores pronunciam o nome dessa localidade da seguinte maneira: Córrego D'ema ou “Córgo D'ema". A irmandade ali existente é a família com o sobrenome da Costa, que ocupa também a área da localidade da Cabeceira.

Na localidade Cabeceira, os primeiros moradores foram da família de sobrenome da Costa. Eles vieram de Mimoso e compraram uma propriedade de 611 ha de terra. A terra foi dividida entre filhos, sobrinhos e netos e o morador que hoje representa essa família, Seu Domício, possui 22,5 ha. Esse morador explicou que a localidade possui esse nome, porque ali é área de nascente de rios; essa área abrange a sua propriedade e as dos seus vizinhos. A localidade Cabeceira faz divisa com a Localidade Tanquinho e Localidade Córrego D'ema.

Durante a pesquisa, foram registrados os espaços que as pessoas utilizam para construir o sentimento de pertencer à comunidade. Espaços esses que facilitam a interação entre as pessoas e fortalecem a idéia de pertencimento de uma comunidade a seu território. Na Tabela 1 é possível visualizar alguns espaços sociais das pessoas das comunidades.

Nesses espaços de convivência social ocorrem encontros de parentes, amigos, vizinhos, cultos ao sagrado, jogos, namoros, brincadeiras e conversas sobre acontecimentos de dentro e de fora das comunidades e algumas dessas atividades só ocorrem em locais específicos, como no caso da "carreira" que é uma manifestação social promovida pelos irmãos Emiliano e Sílvio, que são realizados na localidade Tanquinho.

Porém, não só existem relações harmoniosas ou festivas nesses espaços, há também situações conflituosas, que não chegam a confrontos diretos, mas que provocam desconforto na grande maioria dos moradores das comunidades, como por exemplo, o conflito existente entre o morador da Localidade Tanquinho que é dono da única linha de ônibus da região e a população usuária que reclamou da tarifa cobrada, declarando-a abusiva.

Outro conflito observado se dá pela influência das igrejas pentecostais na região. Os moradores alegam que antes da instalação dessas igrejas, ocorriam mais festas na comunidade, o que unia mais a população. Alguns moradores dizem que determinadas festas pararam de acontecer pois seus realizadores converterem-se às igrejas pentecostais. De acordo com Bombardi (2004), quando ocorre a diminuição na participação em festas realizadas nas igrejas ou para a igreja, o espaço escolar assume essa responsabilidade como uma maneira encontrada pela comunidade para que todas as pessoas participem, independente da religião. Todavia, esse fato não ocorre nas duas comunidades, pois, além da expansão das igrejas pentecostais, outros motivos concorrem para que não haja a realização dos festejos, como o desinteresse dos jovens pelas tradições e o empobrecimento da região, pois as pessoas não conseguem mais contribuir financeiramente para a realização dessas festas. Realidade também comum em comunidades de camponeses tradicionais na região da Morraria - Cáceres/MT, onde os jovens perderam a vontade de participar das festas religiosas da região e muitos moradores deixaram de realizar essas festas devido à dificuldade financeira e optaram em realizar as rezas em casa, em sinal de devoção (SILVA, 2007).

De acordo com Queiroz (1973), as festas religiosas estabelecem a identidade ao camponês e a certeza de pertencer à comunidade, elas servem como ponto de convívio social, assim como a escola e o bar. O modo de viver camponês vem passando por profunda transformação devido às mudanças 
trazidas pela modernidade agrícola, expansão dos meios de comunicação e a expansão capitalista. A religiosidade, por estar intimamente ligada a esse modo de viver camponês, serve de espelho para traduzir como essas mudanças estão empobrecendo e, de certa forma, extinguindo aspectos mais tradicionais do campesinato.

Tabela 1 - Indicadores de organização sócio-territorial das comunidades de Sangradouro e São Sebastião.

\begin{tabular}{|c|c|c|c|}
\hline Localidade & Atividade Social & Espaço Social & Descrição \\
\hline \multirow{6}{*}{ Sangradouro } & Torneio de Futebol & Campo da igreja & $\begin{array}{l}\text { É o campo de futebol comunitário, localizado atrás da } \\
\text { igreja São Benedito. Ocorrem torneios de futebol } \\
\text { masculino e feminino, no periodo das férias escolares. } \\
\text { A área do campo foi cedida pelo morador Joaquim } \\
\text { Laurindo do Nascimento. }\end{array}$ \\
\hline & Bar & Casa do Benedito e Joaní & $\begin{array}{l}\text { O bar faz parte da casa. É o único bar dessa } \\
\text { localidade. Nesse estabelecimento são vendidos } \\
\text { doces, biscoitos, refrigerantes, bebidas alcoólicas e } \\
\text { alimentos básicos como arroz, feilão, óleo. }\end{array}$ \\
\hline & $\begin{array}{l}\text { Festa Junina e Festa da } \\
\text { Primavera }\end{array}$ & \multirow[t]{2}{*}{$\begin{array}{l}\text { Escola Municipal José Maria } \\
\text { da Costa }\end{array}$} & $\begin{array}{l}\text { A escola atende o ensino de } 1^{\underline{a}} \text { a } 4^{\underline{a}} \text { séries do Ensino } \\
\text { Fundamental. Na escola sempre acontecia a festa } \\
\text { Junina e festa da Primavera; já faz oito anos que não } \\
\text { ocorre mais devido à falta de recursos da população. }\end{array}$ \\
\hline & Ponto de telefone público & & $\begin{array}{l}\mathrm{Na} \text { frente da escola está o único ponto de telefone } \\
\text { público da região. }\end{array}$ \\
\hline & Prainha da Dona Judite & Propriedade da Dona Judite & $\begin{array}{l}\text { Na propriedade da Dona Judite tem um rio e um } \\
\text { barzinho onde as famílias vão para ouvir música e } \\
\text { tomar banho. }\end{array}$ \\
\hline & Pique Jovem & Propriedade do Seu Joacir & $\begin{array}{l}\text { É o piquenique feito na beira do rio só para os jovens } \\
\text { solteiros das localidades; já acontece há quatro anos, } \\
\text { semore no comeco das áquas. }\end{array}$ \\
\hline Cantão & & Cemitério & $\begin{array}{l}\text { Um antigo e pequeno cemitério. Não há mais enterros } \\
\text { ali. }\end{array}$ \\
\hline \multirow{3}{*}{$\begin{array}{l}\text { Vila São } \\
\text { Sebastião }\end{array}$} & Ensino & Escola Municpal Perdição & $\begin{array}{l}\text { Atende o ensino de } 1^{\text {a }} \text { a } 4^{a} \text { séries do Ensino } \\
\text { Fundamental. A professora é a Eliane, moradora nativa }\end{array}$ \\
\hline & Bar & $\begin{array}{l}\text { Casa do Edison e } \\
\text { Professora Eliane } \\
\end{array}$ & $\begin{array}{l}\text { Esse bar disponibiliza uma maior quantidade de } \\
\text { produtos consumíveis do que o bar de Sangradouro. }\end{array}$ \\
\hline & $\begin{array}{l}\text { Reuniões entre os } \\
\text { moradores }\end{array}$ & Centro Comunitário & Desativado. \\
\hline \multirow{4}{*}{ Tanquinho } & Transporte de linha & Casa do Silvio & $\begin{array}{l}\text { Ida para Cuiabá toda } 2^{\mathrm{a}} \text { feira e } 5^{\mathrm{a}} \text { feira. Sai de } \\
\text { Sangradouro às } 6 \mathrm{~h} \text { da manhã, com destino ao } \\
\text { Atacadão do Tijucal. Retorna de Cuiabá às } 16 \mathrm{~h} \text {, a } \\
\text { passagem é de } R \$ 8.00 \text {. } \\
\text { Aos sábados, transporta os feirantes, a passagem é } \\
\mathrm{R} \$ 25,00 \text {; sai de Sangradouro às } 5 \mathrm{~h} \text { para a feira do } \\
\text { Praeiro e retorna às } 15 \mathrm{~h} \text {. }\end{array}$ \\
\hline & Transporte escolar & Casa do Silvio & $\begin{array}{l}\text { Seu Sílvio presta serviço à prefeitura de Santo Antônio } \\
\text { e recebe uma taxa para manter o transporte escolar na } \\
\text { região. O ônibus fica estacionado na casa do seu } \\
\text { Sílvio. }\end{array}$ \\
\hline & \multirow[t]{2}{*}{$\begin{array}{l}\text { Carreira ou corrida com } \\
\text { cavalos }\end{array}$} & \multirow[t]{2}{*}{ Casa do Emiliano } & $\begin{array}{l}\text { Seu Emiliano faz carreira (corrida) com cavalo. Esse } \\
\text { evento une pessoas da Localidade Tanquinho e de } \\
\text { outras localidades. No dia da carreira chega a juntar } \\
200 \text { a } 300 \text { pessoas para assistir. É algo que aprendeu } \\
\text { com o pai. }\end{array}$ \\
\hline & & & $\begin{array}{l}\text { Existe aposta em dinheiro, mas também apostas de } \\
\text { vaca, porco, galinha. A carreira ocorre há cada dois } \\
\text { meses, ou quando ocorre um churrasco entre a família. }\end{array}$ \\
\hline
\end{tabular}


Certos espaços sociais só existem em decorrência do cumprimento de uma promessa a algum santo, como as festas de promessa (Tabela 2). Um exemplo é a história do "Seu Tuca", de 85 anos, um morador da localidade Cabeceira. Conta ele que, no tempo da sua mãe, era costume fazer a festa de São João na sua casa. Depois de casado, seu filho nasceu muito doente e, ao ver a imagem de São Benedito com o menino Jesus no colo, o mesmo desejou que curasse seu filho e que ele fosse forte e bonito como o menino Jesus.

O informante ressaltou que antes desse acontecimento, ele e sua esposa já haviam visitado médico e benzedeira e nada adiantou. A cura só foi realizada após ter rezado para o santo. Com isso, o Seu Tuca abandona a festa de São João para dedicar-se à Festa de São Benedito. Tal fato ocorreu há 56 anos: hoje, o filho que recebeu o milagre também possui a imagem de São Benedito em sua casa.
A noção espacial e social de comunidade que o camponês constrói é gerada a partir do conhecimento das estruturas físicas que compõem esse espaço, como a localização da igreja e os lugares habitados pelas famílias, das relações familiares, das relações de trabalho e religiosas que constituem as coordenadas que orientam a percepção desse camponês sobre o território ocupado (QUEIROZ, 1973; AGUIAR, 2006).

Além disso, a relação comercial que é estabelecida com a cidade e as relações sociais com parentes que moram fora da comunidade favorecem uma percepção mais abrangente da região, de que a comunidade é parte integrante. Esses mesmos fatores também interferem na organização interna da unidade de produção, principalmente na tomada de decisão do camponês por um determinado cultivo ou criação, na forma como vai distribui-los pela propriedade e também na maneira como vai nomear esse novo espaço.

Tabela 2 - Indicadores de organização socioterritorial das comunidades de Sangradouro e São Sebastião.

\begin{tabular}{|c|c|c|c|}
\hline Localidade & Manifestação & Espacio Social & Descrição \\
\hline \multirow{2}{*}{ Sangradouro } & Festa de São Benedito & Igreja São Benedito & $\begin{array}{l}\text { Esta festa ocorre sempre no segundo domingo } \\
\text { do mês de iulho. }\end{array}$ \\
\hline & $\begin{array}{l}\text { Festa de Nossa Senhora } \\
\text { Aparecida }\end{array}$ & Casa da Dona Judite & Festa de promessa. \\
\hline Cantão & Culto Evangélico & $\begin{array}{l}\text { Igreja Pentecostal da } \\
\text { Vida }\end{array}$ & Essa igreja é muito recente na comunidade. \\
\hline \multirow[b]{2}{*}{ São Sebastião } & Culto Evangélico & $\begin{array}{l}\text { Igreja da Assembléia } \\
\text { de Deus }\end{array}$ & $\begin{array}{l}\text { Na igreja é feita reunião do Ciclo de Oração, } \\
\text { Escola dominical e casamentos. }\end{array}$ \\
\hline & Festa de São Sebastião & Igreja São Sebastião & $\begin{array}{l}\text { Acontece no dia } 20 \text { de janeiro; na festa tem a } \\
\text { missa e o baile, com a dança de cururu, forró e } \\
\text { sertaneja. É o dia em que encontram os } \\
\text { amigos das localidades. }\end{array}$ \\
\hline \multirow[t]{2}{*}{ Tanquinho } & Festa do Senhor Divino & Casa de Ernestina & $\begin{array}{l}\text { Acontece no dia } 1^{\circ} \text { de setembro. Festa de } \\
\text { promessa. }\end{array}$ \\
\hline & Festa de São Miquel & Casa do Seu Miquel & Festa de promessa \\
\hline \multirow[t]{2}{*}{ Cabeceira } & Festa de São Benedito & Casa do seu Tuca & $\begin{array}{l}\text { Festa de promessa. Deve unir em torno de } 150 \\
\text { pessoas; ele tem um amplo espaço em frente } \\
\text { de sua casa e uma varanda de madeira que } \\
\text { está fazendo lateral à sua casa para atender } \\
\text { aos festeiros. } \\
\text { Seu Tuca impôs regras para a realização da } \\
\text { festa em sua casa: primeiro tem que haver a } \\
\text { missa, seguida do almoço e, só mais tarde, } \\
\text { começa o baile (festa). }\end{array}$ \\
\hline & $\begin{array}{l}\text { Festa de Nossa Senhora } \\
\text { de Conceição }\end{array}$ & Casa do Seu Domício & Ocorre em dezembro. Festa de promessa. \\
\hline
\end{tabular}




\section{A história do sistema de produção e o processo de comercialização das comunidades Sangradouro e São Sebastião}

Para descrever a história do sistema de produção e comercialização das comunidades foi preciso dividi-la em três períodos.

$\mathrm{O}$ início caracteriza-se pelo primeiro tipo de sistema de produção que começou antes da década de 20 e persistiu até os meados dos anos 80, quando os moradores transportavam a sua produção utilizando boi de cangalha pelas estradas de cargueiro e levavam suas mercadorias para a região do Coxipó.

O segundo período, entre as décadas de 70 e 80, foi marcado pelas transformações que paulatinamente ocorreram e que modificaram, em parte, o sistema de produção e de comercialização da região. Isso se deu a partir das obras que o governo Municipal e indiretamente o Federal realizou na região.

O terceiro período iniciou no final da década de 80 até o presente, e se distinguiu pela crise e declínio na produção agrícola.

\section{1o período: tempo dos antigos}

Pode-se supor que antes mesmo que a primeira organização territorial estivesse totalmente estabelecida por influência da cultura e da cosmologia, os primeiros moradores começaram a construir, primeiro no plano de idéias e depois na prática, o tipo de sistema agrícola que ali exerceriam. Os critérios para o local e a escolha dos primeiros cultivos, o período das primeiras derrubadas, o tipo de material para a construção das suas casas, tudo estava relacionado ao corpo de conhecimento que esses indivíduos possuíam, possibilitando a eles a capacidade de perceber, conceber e materializar seu território e sistemas produtivos.

Assim, logo que estabelecidas as residências, as roças e realizada a colheita, os camponeses começaram a levar suas mercadorias à cidade de Cuiabá. Na capital, os camponeses faziam as trocas comerciais, vendendo sua produção e comprando produtos como tecidos e mantimentos que não poderiam adquirir de outra forma.

A longa distância para chegar a Santo Antonio de Leverger condicionou essas pes- soas a preferir vender suas mercadorias em Cuiabá. Até hoje os feirantes dessas comunidades vendem seus produtos na capital.

A produção ou mercadoria, como os antigos falavam, era transportada por meio de carro de boi ou boi de cangalha e a cavalo. Nessa época, as estradas eram conhecidas como estradas de boi, "trieiro boiadeiro" ou cargueiro de boi. Esse tipo de locomoção era muito desgastante para os camponeses e era agravado no tempo das chuvas, devido às grandes inundações que impediam a passagem pelas estradas. A viagem dos antigos até Cuiabá demorava dois dias.

A cavalo, ou puxando o carro de boi, o camponês seguia em frente para chegar à região do Coxipó, pois lá já havia um mercado e uma freguesia estável. Em Cuiabá havia um armazém que comprava 3 a 4 arrobas por semana de toucinho salgado; porém tudo era vendido barato, mas como a realidade econômica era outra, havia lucro, conforme relatos colhidos durante a pesquisa de campo.

Os principais produtos vendidos eram mandioca, farinha de mandioca, milho, feijão, arroz, cará, batata doce, banana, galinhas vivas, leitões vivos, toucinho de porco salgado, que transportavam dentro de uma bolsa de couro denominada bruaca. Para aqueles que presenciaram esse período, a descrição foi de uma época de muita prosperidade na região.

Nesse tempo também era comum, assim como hoje, a criação de suínos, aves e gado; a diferença para o sistema produtivo atual está na forma como o gado era criado. Anteriormente, o gado era colocado para pastar em área de uso comum, não havia divisas, nem cercas, o gado era diferenciado apenas pela marca feita a ferro quente.

Nessa época, ao invés de o gado ser mantido em piquetes cercados, eram as roças que precisavam ser cercadas. As roças não precisavam ficar muito longe das casas. Quando isso acontecia, era motivado pela qualidade da terra para plantar e, devido à distância, passavam até uma semana cultivando nessas áreas.

Outro fato era que as pessoas organizavam-se em mutirão para formar as roças. Quando queria começar uma nova roça, o agricultor chamava seus vizinhos e parentes e derrubava a mata, dividindo-a em partes 
para que cada um formasse sua roça. As roças eram separadas apenas por uma divisa de toco.

Os procedimentos utilizados para iniciar uma roça seguem a lógica de derrubada e queima (KERR e POSEY, 1984; POSEY, 1986; COSTA JRet al; 2003; Azevedo 2004b; Godoy, 2004; Mendes, 2005b) e consiste em abertura da área e depois roçada com auxílio da foice; derrubada das árvores com o machado e, posteriormente, os galhos finos e folhas eram queimados. Já os galhos grossos e troncos das árvores eram guardados para lenha ou madeira de construção. Após essas etapas, a terra era preparada com tração animal e com ferramentas manuais para depois plantar. Vale ressaltar que os antigos contam que gostavam de queimar porque ajudava no controle das pragas e aumentava a fertilidade do solo.

\section{2º período: o tempo da abundância}

Depois de alguns anos, entre as décadas de 70 e 80 , houve um incentivo maior do governo na produção agrícola e comercial da região. Depois de realizadas obras como a construção da ponte sobre o rio Aricá Mirim (Bambá), abertura da estrada da comunidade até a BR 364, a chegada da energia elétrica, a construção das escolas, houve, segundo os moradores, uma melhoria nas condições de vida e de comercialização.

Nesse período, os agricultores não comercializavam mais a produção no bairro Coxipó, mas, na feira do bairro Praieiro, pois a ida à Cuiabá tornou-se menos desgastante e rápida. Tão boas foram essas mudanças que a grande maioria dos camponeses que viviam em Sangradouro e Perdição tirava seu sustento quase que exclusivamente da agricultura e da pecuária.

Mudanças também começaram a ocorrer na ocupação territorial das comunidades. Os antigos foram vendendo suas propriedades e se mudando para Cuiabá; os novos moradores começaram a cercar suas terras, e as pastagens de uso comum foram diminuindo. A derrubada de extensas áreas de mata, o uso do fogo na formação de roças de toco e na limpeza e renovação das pastagens foram diminuindo, com a fiscalização dos órgãos ambientais.
Em 1986, através de política de incentivo do governo municipal, houve estímulo para os pequenos agricultores da baixada cuiabana comercializarem seus produtos todos os sábados em diferentes bairros de Cuiabá, com o Projeto "Muxirum". A prefeitura dispunha de uma caminhonete que buscava gratuitamente os feirantes e seus produtos. O Muxirum durou apenas um ano.

As espécies comercializadas pelos feirantes, em Cuiabá, por meio da assistência técnica da EMPAER de Santo Antônio de Leverger, foram: mandioca, milho híbrido, batata-doce, cará, abóbora, abacaxi, banana, hortaliças, melancia, laranja, pocã, limão, mamão, seriguela, caju e também produtos como a farinha de mandioca e rapadura de leite, entre outros produtos. Dos animais, comercializavam, em Cuiabá, a carne de aves e de suínos e o leite.

\section{3ำ período: a crise}

Apesar de o Muxirum ter tido uma durabilidade curta, alguns feirantes de Sangradouro e Perdição continuaram, em número bem menor, a vender seus produtos na feira do Praieiro.

Vários motivos levaram os agricultores a abandonarem a atividade de feirante, entre eles:

- Tarifa do transporte da mercadoria: apenas um ônibus que pertence a um morador da localidade Tanquinho transporta os feirantes para Cuiabá e o valor da passagem é R\$ 25,00;

- Aluguel para a montagem da barraquinha em Cuiabá: o feirante precisa pagar à Associação de Feirantes pela montagem da barraquinha na feira $\mathrm{R} \$$ 8,00 pelo aluguel.

- Mercado consumidor instável: nem todos os feirantes conseguem vender na feira todos os seus produtos, o que gera um prejuízo, já que o material acaba estragando.

Assim, muitos feirantes abandonaram essa atividade para trabalhar em empreiteiras, como diaristas, ou abriram negócios próprios, como bares. Hoje, persiste apenas um feirante da comunidade Sangradouro e seis feirantes da comunidade São Sebastião. Esses 
camponeses levam o mesmo tipo de produção do tempo do Muxirum para a feira de Cuiabá, só que em quantidade bem menor.

\section{Considerações finais}

Por fim, a partir dos relatos de memória desses moradores, pode-se entender que a organização territorial do sistema agrário dessas duas comunidades seja fruto destes três elementos: da relação de parentesco (irmandade, casamentos consanguíneos), da influência das instituições sociais (igreja, escola, bar, festas, feira, mercado, EMPAER, entre outros) na comunidade e dos aspectos naturais (água, vegetação, solo, fauna) que determinam a forma de ocupação e uso dos recursos naturais.

\section{Referências}

ADDISON, E. E. A percepção ambiental da população do município de Florianópolis em relação à cidade.151f. Dissertação (Mestrado em Engenharia de Produção) Centro Tecnológico, Universidade Federal de Santa Catarina, Florianópolis-SC, 2003.

AGUIAR, M. V. de A. El aporte del conocimento local para el desarrolo rural: Un estúdio de caso sobre el uso de la biodiversidad em dos comunidades campesinas tradicionales del Estado de Mato Grosso-Brasil. 744f. Tese (Doutorado em Agroecologia, Campesinato e História) Universidade de Córdoba, Instituto de Sociologia e Estudos Campesinos, Córdoba - Espanha, 2006.

ALTIERI, M. A. ¿Por que estudiar la agricultura tradicional? Revista Agroecología y Desarrollo, Chile, v. 1, n. 1. p. 16-24, 1991.

ALVES, H. S. Percepção dos agricultores em relação ao solo e seu uso, em comunidades tradicionais, da região da Morraria, Cáceres, MT. 390f. Dissertação (Mestrado em Agricultura Tropical) - Universidade Federal de Mato Grosso, Faculdade de Agronomia e Medicina Veterinária, Cuiabá-MT, 2004.

AZEVEDO, R. A. B. de. Indicadores agronômicos em unidades de produção de agricultura familiar. 306f. Tese (Doutorado em Fitotecnia) - Universidade Federal de Viçosa, Departamento de Fitotecnia - Universidade Federal de Viçosa, Viçosa-MG, 2001.

BASTOS, R. Áreas de uso comum por agricultores tradicionais de comunidades da região de Morraria, Cáceres-MT. 139f. Dissertação (Mestrado em Agricultura Tropical) Universidade Federal de Mato Grosso, Faculdade de Agronomia e Medicina Veterinária, Cuiabá- MT, 2004.

BOMBARDI, Larissa Mies. O bairro rural como identidade territorial: a especificidade da abordagem do campesinato na geografia. AGRÁRIA, n. 1, p. 55-95, 2004.

CANDIDO, A. Os parceiros do Rio Bonito: estudo sobre o caipira paulista e a transformação dos seus meios de vida. 34 ed. São Paulo: Duas Cidades, 2001. 217p.

CLAVAL, P. O Território na transição da pós-modernidade. Revista Geographia, Niterói-RJ, n.2, p.7-26, 1999.

COSTA, M. C da. Condicionantes de procedimentos técnicos de agricultores tradicionais de três comunidades da região de Morraria, Cáceres, MT. 2004, 139f. Dissertação (Mestrado em Agricultura Tropical) - Universidade Federal de Mato Grosso, Faculdade de Agronomia e Medicina Veterinária, Cuiabá, 2004.

EMPAER. Levantamento de informações e avaliação diagnóstica da comunidade de Sangradouro. Trabalho Técnico, 2004.

GODOY, D. P. dos S. Estrutura e função dos quintais de unidades de produção das comunidades Nossa Senhora da Guia e Santana, Cáceres-MT. 111f. Dissertação (Mestrado em Agricultura Tropical) - Universidade Federal de Mato Grosso, Faculdade de Agronomia e Medicina Veterinária, Cuiabá, 2004.

LAMARCHE, H. (Coord). A agricultura familiar, 2.ed. Campinas: Editora da Unicamp, v. 1, 1997.

LITTLE, P. E. Territórios sociais e povos tradicionais no Brasil: por uma antropologia da territorialidade. Disponível em: <www.unb.br/ics/dan/Serie322empdf.pdf>. Acesso em: 18 maio 2006.

MENDES, R. R. Manejo e uso da vegetação nativa por agricultores tradicionais da comunidade de Santana, região da Morraria, Cáceres -MT. 104f. Dissertação (Mestrado em Agricultura Tropical) - Universidade Federal de Mato Grosso, Faculdade de Agronomia e Medicina Veterinária, Cuiabá, 2005.

METTRICK, H. Development oriented research in agriculture: an ICRA textbook. Wageningen: ICRA (The International Centre for Development Oriented research in Agriculture), 1993, 291 p.

MIKKELSEN, B. Methods for development work and research: a guide for practitioners. New Delhi: Sage, 1995, 296 p.

OLIVEIRA, R. C. de. Uso e manejo de recursos nos arredores das residências de camponeses: estudo de caso na região de Morraria. 166f. Dissertação (Mestrado em Agricultura Tropical) - Universidade Federal de Mato Grosso, Faculdade de Agronomia e Medicina Veterinária, Cuiabá- MT, 2006.

QUEIROZ, M. I. P. de. O campesinato brasileiro: ensaios sobre civilização e grupos rústicos no Brasil. 2 ed. Petrópolis: Vozes, 1973, 242p.

RAMOS, A. de A. Estratégias de ocupação do espaço e uso de recursos naturais em unidades de produção da comunidade de Santana, Cáceres-MT. 212f. Dissertação (Mestrado em Agricultura Tropical) -Universidade Federal de Mato Grosso, Faculdade de Agronomia e Medicina Veterinária, Cuiabá- MT, 2006.

SHANIN, T. Defining peasants: essays concerning rural societies, expolary economies, and learning from them in the contemporany world. Oxford: British Library. 1990. 340p.

SCHNEIDER, S. Teoria Social, agricultura familiar e pluriatividade. Revista Brasileira de Ciências Sociais, v. 18 n. 51, 2003. 
SILVA, P. J.; ALMEIDA, M. G. Territorialidade e desterritorialidade: os assentamentos rurais e a reterritorialidade do campesinato no espaço agrário do Cerrado mineiro. V CONGRESSO DE CIÊNCIAS HUMANAS LETRAS ARTES. Disponível em: <http:/ / www.ufop.br/ichs / conifes / anais / MPC/ mpc0604.htm>. Acesso em: 19 maio 2006.

SOUZA, J. M. L. O território: sobre espaço e poder, autonomia e desenvolvimento. In: Geografia-conceitos e temas. Rio de Janeiro: Bertrand do Brasil. 1995. p. 77-116.

TOLEDO, V. M. What is ethnoecology? Origin, scope and implications of a rising discipline. Etnoecológica, v.
1, n. 1, 1991. p. 5-21.

VIEIRA, S. N. A unidade de manejo chacra em comunidades agrícolas tradicionais da Morraria em Cáceres, MT. 99f. Dissertação (Mestrado em Agricultura Tropical) Universidade Federal de Mato Grosso, Faculdade de Agronomia e Medicina Veterinária, Cuiabá- MT, 2006. WOLF, E. Sociedades camponesas. Rio de Janeiro: ZAHAR, 1976, 152p.

WOORTMANN, E. F. e WOORTMANN, K. O trabalho na terra: a lógica e a simbólica da lavoura camponesa. Brasília: Ed. UnB, 1997, 192 p. 